\title{
URGENSI CHECKS AND BALANCES KETATANEGARAAN INDONESIA DAN ISLAM
}

\author{
Bustamin ${ }^{1}$, Rony Jaya ${ }^{2}$ \\ ${ }^{1}$ Institut Agama Islam Negeri Batusangkar \\ e-mail: bustamin@iainbatusangkar.ic.id \\ 2 Universitas Islam Negeri Suska Riau \\ e-mail: rony.jaya@uin-suska.ac.id
}

\begin{abstract}
The reform movement opened the door to implementation of the 1945 amendment to the constitution. The urgency of the Indonesian government's control system, which included the legislative, executive and judicial institutions, was quite a concern. This condition is based on the fact that during the Orde Baru the concept of the Trias Politica Montesquieu was castrated by the authorities. Unlike the case of the Islamic constitutional system, the concept of mutual control was much more familiar when Khulafaur Rasyidin Umar bin Khattab called six (six) bigh-ranking friends to find a replacement. This was later considered the first Syura Institute in Islamic history. The purpose of this paper is to recognize the urgency of checks and balances in the Indonesian government system and in the Islamic state administration. This article uses a library research method with a qualitative descriptive approach, which is then analyzed using the interactive analysis model of Miles, Huberman, and Saldana. The results show that following the amendment of the 1945 Constitution, the legislature, including the DPR and the DPD, has taken control of the executive and the Supreme Court and the Constitutional Court as a judicial body can control each other and establish a balance between these institutions. While the Islamic constitutional system in the Figh study of Siyasah was already familiar with the separation of powers and the separation of powers in the institutions of Tasyri'izah, Tanfidriyah and Qada'iyah.
\end{abstract}

Kata Kunci: Checks and Balances, Ketatanegaraan Indonesia dan Islam

\section{PENDAHULUAN}

$P$ ower tends corrupt, but absolute power corrupts absolutely (Budiardjo, 2008). Kendati urgensi menghindari pemusatan kekuasaan yang dapat mengarahkan pada kesewenang-wenangan, sehingga distribution of power (pembagian kekuasaan negara) dan separation of power (pemisahan kekuasaan) harus diwujudkan. (Sunarto, 2016)

Sejarah telah mencatat bahwa rezim Orde Baru telah mengkebiri teori-teori trias politica serta aplikasinya. Sehingga realitas kekuasaan hanya terpusat pada
Presiden. (Rahmatullah, 2013) Maka pandangan kritis lahir dari kalangan akademisi, praktisi maupun masyarakat pada umumnya dengan melihat terjadinya praktek kenegaraan ataupun peraturan dan undang-undang yang tidak sesuai dengan UUD 1945. Sebab ketika itu, Orde Baru mengekang kebebasan pers dan kebebasan mimbar akademis; pembatasan yang keras terhadap organisasi kemasyarakatan dan partai politik serta lembaga legislatif terkesan tersubordinasi oleh eksekutif, ataupun 
ketika terjadi pelanggaran hak asasi masnusia secara mencolok. Sedangkan Presiden Soeharto secara eksplisit menyatakan sikapnya agar tidak mudah mengubah undang-undang. (Budiardjo, 2008)

Pada tahun 1998 reformasi digulirkan dan Orde baru digulingkan. Maka terjadilah perubahan dalam sistem ketatanegaraan Indonesia, di mana UUD 1945 telah diamandemen sebanyak 4 (empat) kali terhitung dari tahun 19992002, demi conditio sine quo nan untuk tegaknya demokrasi, rule of law, pengendalian kekuasaan dan memberikan kebebasan warga negara secara individual dan hak politik partisipatorisnya. (Thaib, 2003)

Konsep trias politica pasca reformasi berjalan dengan cepat, lantas diiringi pula sistem bikameral yaitu DPR RI dan DPD RI bertujuan untuk mempercepat tercapainya pemerintahan yang baik dan tata pemerintahan yang baik (good gavernment and good governance) serta tercapainya check and balances antara lembaga negara khususnya di lembaga legislatif, yang merupakan salah satu unsur terpenting dalam penyelenggaraan Negara. (Pirmansyah, 2014)

Sistem checks and balances berfungsi untuk saling mengontrol lembaga kekusaan satu dengan lainnya, agar terhindar dari tindakan-tindakan hegemonik, tiranik dan sentralisasi kekuasaan. Sistem ini mencegah terjadinya overlapping antara kewenangan yang ada (Rahmatullah, 2013) antara bidang eksekutif, legislatif maupun yudikatif. (Montisa Mariana, 2017)

Pelaksanaan check and balances antar lembaga negara tersebut diharapkan agar kekuasaan tidak terpusat pada satu lembaga negara saja seperti yang pernah terjadi dalam sistem ketatanegaraan Indonesia di masa lalu (executive or legislative heavy). (A.R, 2012) Oleh karena itu, maka urgensi penguatan sistem check and balances terhadap lembaga negara, baik lembaga legislatif, eksekutif dan yudikatif harus terus dipekuat demi terwujudnya sistem ketatanegaraan Indonesia yang good governance and clean governance.

Pada dasarnya sistem checks and balances, Presiden sebagai kepala eksekutif memiliki kedudukan yang sederajat, tetapi saling mengendalikan dengan lembaga Parlemen sebagai pemegang kekuasaan legislatif. Sesuai dengan prinsip presidensial bahwa Presiden tidak dapat membubarkan Parlemen, begitu sebaliknya Parlemen juga tidak dapat menjatuhkan Presiden. Namun Parlemen hanya dapat menuntut pemberhentian Presiden jika Presiden terbukti melakukan pelanggaran hukum; itupun dibatasi oleh konstitusi hanya untuk jenis-jenis tindak pidana tertentu saja (Mawardi, 2008) Pada kasus pemberhentian Presiden Gusdur oleh Parlemen dengan alasan beliau telah melanggar konstitusi, namun kenyataannya tidak demikian, karena pengadilan telah memutuskan bahwa beliau tidak melanggar konstitusi. Akan tetapi pelenggseran beliau lebih kepada persoalan aspek politik atau kekuatan legislatif yang dominan sehingga menggaburkan prinsip check and balances, (Suparman, 2016) sedangkan pada lembaga yudikatif seringnya terjadi intervensi dari pihak eksekutif untuk mengamankan kekuasaan.

Sedangkan dari kacamata sistem ketatanegaraan Islam, diketahui bahwa Islam adalah agama universal yang 


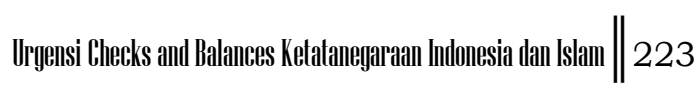

ajarannya mengandung prinsip-prinsip dasar kehidupan termasuk politik dan ketatanegaraan. (Shobron, 2016) Kendati, dalam referensi sejarah Islam tidak dijumpai ketentuan yang pasti bagaimana bentuk dan konsep sistem pemerintahan yang dikehendaki, sehingga menimbulkan belbagai penafsiran serta upaya untuk merealisasikanya. (Paydar, 2003)

Para cendikiawan muslim mulai fokus kajiannya terhadap kebijaksanaan persoalan pengurusan kenegaraan yang berdasarkan syariat (siyasah syar'iyyah) (Iqbal, 2014). Khallaf mengatakan siyasah syar'iyyah adalah pengelolaan masalahmasalah umum bagi pemerintahan Islam yang menjamin terciptanya kemaslahatan dan terhindarnya kemudaratan dari masyarakat Islam, dengan tidak bertentangan dengan ketentuan syariat Islam dan prinsip-prinsipnya yang umum, meskipun tidak sejalan dengan pendapat para ulama mujtahid. Khallaf lebih dalam menjelaskan yang dimaksud dengan masalah umum umat Islam adalah segala hal yang membutuhkan pengaturan dalam kehidupan mereka, baik di bidang perundang-undangan, keuangan dan moneter, peradilan, eksekutif, masalah dalam negeri ataupun hubungan international. Berdasarkan pandangan Khallaf tersebut, dapat dikatakan bahwa Islam sejatinya telah meletakkan dasar-dasar sistem ketatanegaraan sendiri.

Didasarkan argumentasi di atas, maka bagaimana urgensi checks and balances dalam sistem ketatanegaraan Indonesia dan bagaimana pula prinsipprinsip checks and balances dalam ketatenegaraan Islam, menjadi menarik untuk dikaji untuk menemukan titik terangnya.

\section{METODE PENELITIAN}

Penelitian ini menggunakan library research dengan menelusuri dan mengkaji karya-karya yang terkait dengan persoalan yang dikaji kemudian memuat kajian tentang penelitian. (Zed, 2007) Jenis data penelitian adalah data sekunder yaitu dari buku-buku, jurnal, penelitian terdahulu yang mengkaji persoalan terkait dengan urgensi checks and balances dalam sistem ketatanegaraan yang berlaku di Indonesia dan sistem ketatanegaraan Islam. Pendekatan penelitian deskriptif kualitatif yaitu bertujuan untuk menggambarkan dan meringkas berbagai kondisi, situasi, dan variabel yang penelitian. (Bungin Burhan, 2001) Selanjutnya data kualitatif tersebut dianalisis berdasarkan interactive model of analysis Miles, Huberman, dan Saldana yaitu data condensation, Data collection, Data display and conclusions. (Miles, Huberman, 2014)

\section{HASIL DAN PEMBAHASAN}

Dalam teori pembagian kekuasaan, Montesquiue membagi kekuasaan menjadi 3 (tiga) yakni lembaga eksekutif, legislatif dan yudikatif beserta wewenang dan fungsi lembaga tersebut. Lantas, Van Vollen Hoven telah mengembangkan trias politica demikian menjadi 4 (empat) yakni: pemerintah (bestuur), pengawasan (regeling), pengaturan (politie), dan penyelesaian sengketa (rechtspraakjjustitie). (Ridwan, 2007)

Undang-undang Dasar 1945 sebagai wujud konstitusi I ndonesia telah mengamanatkan ajaran pembagian 
kekuasaan (distribution of power) dengan menekankan urgensi fungsi lembaga dan konsep checks and balances juga menekankan hubungan saling mengawasi dan mengendalikan antar belbagai lembaga negara terhadap fungsi dan wewenang lembaga tersebut. Hasil dari amandemen UUD 1945 telah memberikan titik terang terhadap urgensi penerapan checks and balances dalam sistem ketatanegaraan Indonesia.

\section{A. Checks and balances Sistem Ketatanegaraan Indonesia}

Salah satu gagasan perubahan ketika era reformasi yang didegungkan adalah usulan tentang sistem dan mekanisme checks and balances di dalam sistem politik ketatanegaraan. Usulan ini menjadi urgen karena selama era dua orde (orde lama dan baru) sebelumnya dapat pastikan bahwa checks and balances itu tidak ada. (Moh Mahfud MD, 2011)

Pada masa orde baru, dimana pembuatan Undang-Undang (UU) misalnya seluruhnya didominasi oleh eksekutif, baik proses inisiatifnya maupun pengesahannya. Bukan hanya itu, tidak pernah ada Rancangan Undang-Undang (RUU) datang dari inisiatif DPR. Bahkan RUU yang semula berasal dari Presiden (eksekutif) pernah juga ditolak untuk disahkan oleh presiden sendiri setelah disetujui oleh DPR. (Moh Mahfud MD, 2011)

Terjadinya dominasi eksekutif yang begitu kuat dalam membuat, melaksanakan dan menafsirkan UU sehingga sistem politik yang executive heavy karena tidak ada lembaga yang dapat membatalkan UU. Tidak adanya peluang atas UU oleh lembaga yudisial dalam apa yang dikenal sebagai judicial review atau (constitutional review) seperti saat ini. Akan tetapi review atas UU hanya dilakukan oleh lembaga legislatif melalui legislative review atau political review, padahal lembaga legislatif didominasi oleh eksekutif (Presiden).

Distribusi kekuasaan merupakan suatu hal yang penting dalam membangun sistem ketatanegaraan Indonesia. Mahfud MD mengatakan bahwa Salah satu kelemahan dari UUD 1945 sebelum amandemen adalah tidak adanya mekanisme checks and balances (Sunarto, 2016). Sehingga pasca amandemen UUD 1945 yang dilakukan sebanyak 4 (empat) kali dari Tahun 1999-2002. menjadikan lembagalembaga negara menjadi kondusif dan tentunya menghilangkan kekuasaan superior dibandingkan yang lainnya. (Montisa Mariana, 2017) Karena lahirnya lembaga-lembaga yang dapat berfungsi sebagai checks and balances yaitu:

\section{Majelis Permusyawaratan Rakyat (MPR)}

Berdasarkan hasil amandemen UUD 1945 dalam Pasal 2 Ayat 1, 2, dan 3 menyebutkan bahwa MPR adalah: 1) Majelis Permusyawaratan Rakyat terdiri atas anggota-anggota Dewan Perwakilan Rakyat, dan anggota Dewan Perwakilan Daerah yang dipilih melalui pemilihan umum dan diatur lebih lanjut dengan undang-undang; 2) Majelis Permusyawaratan Rakyat bersidang sedikitnya sekali dalam lima tahun di Ibu Kota Negara; dan 3) Segala putusan Majelis Permusyawaratan Rakyat ditetapkan dengan suara 
yang terbanyak. Sedangkan Pasal 3 Ayat 1, 2, dan 3 menyebutkan bahwa: 1) Majelis Permusyawaratan Rakyat berwenang mengubah dan menetapkan Undang-undang Dasar; 2) Majelis Permusyawaratan Rakyat melantik Presiden dan/atau Wakil Presiden; dan 3) Majelis Permusyawaratan Rakyat hanya dapat memberhentikan Presiden dan/atau Wakil Presiden dalam masa jabatannya menurut UndangUndang Dasar (Indonesia, 1945)

Konsekuensi amandemen UUD

1945 membawa beberapa perubahan terhadap kedudukan MPR. Yakni:

1. Pergeseran kedudukan MPR dari lembaga tertinggi menjadi lembaga tinggi Negara.

2. Perubahan tentang kenggotaan MPR. Sebelum UUD 1945 diamandemen kenggotaan MPR terdiri dari seluruh anggotan DPR, ditambah dengan utusan daerah, dan utusan golongan.

3. Perubahan tentang kewenangan MPR. Sebelum amandemen UUD 1945 MPR, mempunyai wewewang memilih presiden dan/atau wakil Presiden; melantik Presiden dan/atau Wakil Presiden; melakukan sidang istimewa untuk memberhentikan Presiden dan/atau wakil presiden dalam masa jabatannya jika Presiden dan/atau wakil Presiden melanggar konstitusi, dan mengubah UUD dan artinya menghilangkan kewenangan dari MPR untuk menetapkan GBHN, dan mengangkat Presiden. (Warjiati, 2012)
Dipertegas Asshidiqqie bahwa, MPR adalah institusi lembaga parlemen Indonesia. Sebagai kedaulatan rakyat Indonesia disalurkan melalui lembaga MPR, namun strukturnya diorganisasikan secara bicameral, yaitu DPR dan DPD. Sehingga dapat simpulkan bahwa MPR hanya memiliki keterkaitan secara lembaga dengan DPR, DPD dan Presiden.

\section{Dewan Perwakilan Rakyat (DPR)}

Pasca amandemen UUD 1945 DPR semakin diperkuat fungsinya sebagai legislations function, budgeting function and controlling function. Sebelumnya, DPR hanya berhak memberikan persetujuan saja. Setelah amandemen, pemerintah tetap berhak mengajukan RUU, dan apabila RUU sudah disetujui oleh DPR namun pemerintah tidak mensahkannya, RUU tersebut tetap menjadi UU (Montisa Mariana, 2017)

Sebagai bentuk implementasi sistem check and balances DPR memiliki hubungan erat dengan DPD dalam menyusun RUU yang berkaitan dengan daerah. Kendati DPR juga harus mendengarkan saran DPD berkaitan dengan penyusunan RAPBN. Sedangkan dengan Presiden, DPR memiliki kewenangan untuk mengawasi jalannya pemerintahan, jalannya pelaksanaan dari APBN dan UU. Selain itu, berkaitan dengan adanya check and balances antar lembagalembaga negara telah diatur dalam kewenangan dengan Pasal 24A; Pasal 24B; Pasal 7B; Pasal 24A; Pasal 
24B; dan Pasal 7B Amandemen UUD 1945.

\section{Dewan Perwakilan Daerah (DPD)}

Hasil Amandemen UUD 1945 melahirkan lembaga DPD yang kemudian disebut sistem bikameral. DPD yang anggota-anggotanya dipilih langsung melalui pemilu ternyata di dalam konstitusi hanya diberi fungsi yang sangat sumir dan nyaris tak berarti jika dibangdingkan dengan biaya politik dan proses perekrutannya yang demokratis. Perbedaan DPD dan DPR misal DPR diatur dalam tujuh Pasal Amandemen UUD 1945 (Pasal 19 sampai dengan Pasal 22) sedangkan DPD hanya diatur dalam 2 (dua) Pasal (Pasal 22 c dan Pasal 22 D). Memang dalam UUD disebutkan secara tegas bahwa DPR memiliki fungsi sebagai legislasi, anggaran dan pengawasan, maka DPD mempunyai fungsi tersebut tapi tidak secara penuh. Dalam bidang legislasi DPD tidak dapat ikut menetapkan UU sebagaimana layaknya lembaga perwakilan rakyat, sebab Pasal 20 ayat (1) sudah megunci bahwa yang memegang kekuasaan membentuk UU adalah DPR. (Moh Mahfud MD, 2011)

Pasal 22 D ayat (1) dan (2) menyebutkan kewenangankewenangan DPD yaitu, dapat mengajukan Rancangan UU, ikut membahas rancangan UU, memberi pertimbangan dan dapat melakukan pengawasan (Indonesia, 1945) didasarkan dengan itu, maka untuk memperbaiki sistem ketatanegaraan Indonesia lebih baik perlunya penyamaan wewenang antara
DPR dan DPD sehingga sistem check and balances berjalan dengan baik.

\section{Mahkamah Agung (MA)}

MA salah satu lembaga negara yang memilliki kekuasaan untuk menyelenggarakan peradilan untuk menegakkan hukum dan keadilan yang termaktub pada pasal 24 ayat 1 . Selain itu, Pasal 24 A Ayat 1 menyebutkan bahwa MA berwenang mengadili pada tingkat kasasi, menguji peraturan perundangundangan di bawah undang-undang terhadap undang-undang, dan mempunyai wewenang lainnya yang diberikan oleh Undang-Undang.

\section{Mahkamah Konstitusi (MK)}

Menurut Janedjri M. Gaffar pembentukan MK didorong dan dipengaruhi oleh kondisi faktual yang terjadi dalam sistem ketatanegaraan yakni: (1) sebagai konsekuensi dari perwujudan negara hukum yang demokratis dan negara demokrasi yang berdasarkan hukum; (2) Pasca Perubahan Kedua dan Perubahan Ketiga, UUD 1945 telah mengubah relasi kekuasaan dengan menganut sistem pemisahan kekuasaan (separation of powers) berdasarkan prinsip checks and balances dan (3) Kasus pemakzulan (impeachment) Presiden Abdurrahman Wahid oleh MPR pada Sidang Istimewa MPR pada 2001, mengilhami pemikiran untuk mencari mekanisme hukum yang digunakan dalam proses pemberhentian Presiden dan/atau Wakil Presiden agar tidak sematamata didasarkan alasan politis semata. (Gaffar, 2009) 
Senada menurut Afiuka Hadjar dkk, (Pigome, 2011) terdapat 4 (empat) alasan yang melatar belakangi pembentukan Mahkamah Konstitusi yaitu:

a. Paham Konstitusionalisme adalah suatu paham yang menganut adanya pembatasan kekuasaan. Paham ini memiliki dua esensi yaitu sebagai konsep negara hukum bahwa hukum mengatasi kuasaan negara, hukum akan melakukan kontrol terhadap politik serta konsep hak-hak sipil warga negara menyatakan bahwa kebebasan warga negara dan kekuasaan negara dibatasi oleh konstitusi;

b. Sebagai mekanisme check and balance, dimana sebuah sistem pemerintahan yang baik antara lain ditandai dengan adanya mekanisme check and balance dalam penyeleggaraan kekuasaan. Memungkinkan adanya saling kontrol antara cabang-cabang keuasaan yang ada dan menghindari tindakan-tindakan tiran dan desentralisasi kekuasaan untuk menjaga agar tidak terjadi tumpang tindih antar kewenangan yang ada. didsarkan pada prinsip negara hukum maka sistem kontrol yang relevan adalah sistem kontrol judicial.

c. Penyelenggaraan negara yang bersih, bilamana sistem pemerintahan yang baik meniscayakan adanya penyelenggaraan negara yang bersih; d. Perlindungan hak asasi manusia yang menegaskan bahwa kekuasaan yang tidak terkontrol, seringkali melakukan tindakan semena-mena dalam penyelenggaraan dan tidak melakukan hak asasi manusia.

MK berfungsi untuk menjamin tidak akan ada lagi produk hukum yang keluar dari koridor konstitusi sehingga hak-hak konstitusional warga terjaga dan konstitusi itu sendiri terkawal secara konstitusionalitas. Dalam rangka menguji apakah suatu undang-undang bertentangan atau tidak dengan konstitusi, maka dilakukan judicial review. Selain itu, MK dapat berfungsi: (1) memutus sengketa antarlembaga negara, (2) memutus pembubaran partai politik, dan (3) memutus sengketa hasil pemilu. (Gaffar, 2009)

\section{Badan Pemeriksa Keuangan (BPK)}

Bedasarkan amandemen UUD 1945 menyatakan bahwa Anggota BPK dipilih DPR melalui pertimbangan DPD. Lantas BPK memiliki wewenang untuk mengawasi APBN dan APBD serta menyampaikan hasilnya tersebut kepada DPR dan DPD. Sedangkan BPK berkedudukan di ibukota negara dan memiliki perwakilan di setiap propinsi.

\section{Komisi Yudisial (KY)}

Berdasarkan UUD 1945 Pasal 24 B bahwa Komisi Yudisial bersifat mandiri yang berwenang mengusulkan pengangkatan hakim agung dan 
mempunyai wewenang lain dalam rangka menjaga dan menegakkan kehormatan, keluhuran martabat, serta perilaku hakim.

Posisi konstitusional KY dalam hasil Amandemen UUD 1945 memiliki legalitas yang sama kuat dengan lembaga-lembaga negara dalam rumpun sistem peradilan (Yudikatif). Kehadiran KY diakui sebagai upaya menciptakan fungsi check and balance dalam sistem pengawasan di peradilan Kehadiran KY sangat diharapkan karena masyarakat kehilangan kepercayaan pada institusi peradilan. peran pengawasan internal yang dilakukan MA tidak efektif, karena kerap digunakan sebagai upaya melindungi oknum yang berbuat salah atas nama semangat korps. (Thontowi, 2011)

\section{B. Checks and Balances Sistem Ketatanegaraan Islam}

Islam sebagai agama yang sempurna dan menyeluruh, sudah sepatutnya memiliki peran utama dalam kehidupan politik atau sistem ketatanegaraan dalam sebuah negara, (Kun Budianto, 2017) sebagaimana diketahui bahwa dalam pemerintahan Islam para penguasa diwajibkan untuk meminta pendapat kepada umatnya dalam segala perkara umum, musyawarah adalah kewajiban yang diwajibkan atas para penguasa juga rakyat. Penguasa harus bermusyawarah dalam setiap perkara pemerintahan, administrasi, politik, dan pembuatan Undang-undang berkenaan dengan kemaslahatan individu dan apalagi untuk kemaslahatan umum. (Khaliq, 2005)
Sejarah Islam telah mencatat bahwa dalam pengangkatan Amirul Mukminin pertama melalui proses musyawarah. Ibnu al-Atsir dalam kitabnya Al-Kamil fi Tarikh menceritakan suatu peristiwa penting yaitu pengangkatan Abu Bakr r.a. sebagai khalifah. Terjadi ketegangan antara orang-orang ansar yang berusaha mengangkat Saad bin Ubaidah menjadi khalifah sedangkan orang-orang muhajirin mengatakan yang layak mengantikan Rasulullah dari pihak Muhajirin karena merekalah yang paling utama. Singkatnya terjadi proses diskusi (musyawarah) akhirnya Abu Bakar dibai'at menjadi khalifah pertama pasca wafatnya Rasulullah. (A.Djazuli, 2003)

Hamka memandang bahwa syura atau musyawarah menjadi pokok dalam pembangunan masyarakat dan negara Islam (Shobron, 2016) sejalan dengan pendapat Abu A'la al-Maududi menyebut syura dengan ahl al-hall wa al-aqd, ahl syura, juga menyebutnya dengan "dewan penasehat" (consultative assembly) (A.Djazuli, 2003) didasarkan pendapat tersebut bahwa konsep check and balances dalam ketatageraan Islam telah dikenal walaupun belum dijelaskan secara spesifik bagaimana penerapannya.

Namun ketika dirujuk pendapat Abdul kadir Audah menyebutkan secara eksplisit praktek ketatanegaraan Islam yaitu: (1) Al-sultah al-Tanfihiyah (eksekutif) yang dipimpin oleh imam; (2) Al-sultah al-Tasri'iya (legislatif) dipimpin oleh ulil amri; (3) Al-sultah alqadla'iyah (yudikatif) dipegang oleh hakim; (4) Al-sulthah al-Maaliyah (Bank Sentral) dipimpin oleh imam; 
Urgensis Checks and Balances Ketatannegaraan Indonnesia dann Istam || 229

dan (5) Al-sulthah al-Mu'raqabah (lembaga pengawasan) dipimpin oleh syura, ulama dan fuqaha.(Audah, 1957)

Dalam wacana fiqh siyasah misalnya dalam bukunya Muhammad Iqbal dengan judul "Fiqh Siyasah Kontekstualisasi Doktrin Politik Islam" mengatakan bahwa trias politica telah ada sejak Rasulullah Muhammad SAW di Madinah yaitu disebut juga sulthah al-tasyri'iyyah (Kekuasaan Legislatif), sulthah al-thanfidziyah (kekuasaan eksekutif), Sulthah al-qadha'iyyah (Kekuasaan Yudikatif). (Iqbal, 2014)

\section{Sulthah Al-tasyri'iyyah.}

Dalam kajian fiqh siyasah legislasi atau kekuasaan legislatif disebut juga dengan sulthah altasyri'iyyah yaitu kekuasaan pemerintah Islam dalam membuat dan menetapkan hukum. Dalam konteks ini kekuasaan legislatif (sulthah al-tasyri'iyyah) berarti kekuasaan atau kewenangan pemerintah Islam untuk menetap kan hukum yang akan diberlakukan dan dilaksanakan oleh masyarakatnya berdasarkan ketentuan yang telah diturunkan Allah SWT dalam Syari'at Islam. Orang-orangyang duduk dalam lembaga legislatif ini terdiri dari para mujtahid dan ahli fatwa (mufti) serta parapakar dalam berbagai bidang. Unsur legislasi dalam fiqh siyasah dapat dirumuskan sebagai berikut:

1. Pemerintah sebagai pemegang kekuasaan untuk menetapkan hukum yang akan diberlakukan dalam masyarakat Islam;
2. Masyarakat Islam yang akan melaksanakannya;

3. Isi peraturan atau hukum itu sendiri yang harus sesuai dengan nilai-nilai dasar syariat Islam.

\section{Sulthah Al-thanfidziyah.}

Menurut Al-Maududi,lembaga eksekutif dalam Islam dinyatakan dengan istilah ulal-amr dan dikepalai oleh seorang Amir atau Khalifah. istilah ulal-amr tidak hanya terbatas untuk lembaga eksekutif saja melainkan juga untuk lembaga legislatif, yudikatif dan untuk kalangan dalam arti yang lebih luas lagi. Namun dikarenakan praktek pemerintahan Islam tidak menyebut istilah khusus untuk badan-badan di bawah kepala negara yang bertugas. Sejak masa kekhilafahan Umar bin Khattab maka untuk hal ini istilah ulal-amr mengalami penyempitan makna untuk mewakili lembaga-lembaga yang hanya berfungsi sebagai eksekutif. Sedangkan untuk kepala negara, alMaududi menyebutnya sebagai Amir dan dikesempatan lain sebagai Khalifah. (Al-Maududi A.A., 1993)

\section{Sulthah Al-qadha'iyyah}

Dalam konsep Fiqh Siyasah, kekuasaan yudikatif ini biasa disebut sebagai sulthah al qadha'iyyah. Kekuasaan kehakiman adalah untuk menyelesaikan perkara-perkara perbantahan dan permusuhan, pidana dan penganiayaan, mengambil hak dari orang durjana dan mengembalikannya kepada yang punya, mengawasi harta wakaf dan 
persoalan-persoalan lain yang diperkarakan di pengadilan. Sedangkan tujuan kekuasaan kehakiman adalah untuk menegakkan kebenaran dan menjamin terlaksananya keadilan serta tujuan menguatkan negara dan menstabilkan kedudukan hukum kepala negara.

Penetapan syariat Islam bertujuan untuk menciptakan kemaslahatan. Dalam penerapannya (syariat Islam) memerlukan lembaga untuk penegakannya. Karena tanpa lembaga (al-qadha) tersebut, hukumhukum tidak dapat diterapkan.

Dari konsep trias politica tersebut, maka dalam ketatanegaraan Islam telah mengenal dan menerapkan konsep check and balances meskipun dalam prakteknya masih sangat sumir, sehingga membutuhkan intrepretasi konsep yang jelas dan tetap sesuai sumber utamanya yaitu Al-Quran dan Sunnah serta ijtihad para ulama.

\section{KESIMPULAN}

Terjadinya perubahan dalam sistem ketatanegeraan Indonesia merupakan hasil dari reformasi 1998 yang menjadikan lembaga eksekutif, legislatif dan yudikatif berfungsi sesuai kewenangannya masing-masing. Kendati pada lembaga legislatif yang menganut sistem bikameral (DPR dan DPD), di mana DPD belum memiliki kewenangan yang setara dengan DPR maka seyogyanya kedua lembaga negara tersebut memiliki wewenang yang sama agar pelaksanaan check and balances berjalan dengan baik. Selain itu, lembaga peradilan di Indonesia terjadi krisis kepercayaan khusus lembaga MA maka, kehadiran $\mathrm{KY}$ diharapan dapat menciptakan fungsi check and balances dalam sistem pengawasan peradilan di Indonesia menjadi optimal.

Islam sebagai agama yang sempurna dan menyeluruh tidak hanya mengatur persoalan ibadah kepada Allah SWT, akan tetapi seluruh sendi kehidupan manusia telah diatur termasuk juga sistem bernegara. Sedangkan konsep check and balances dalam sistem ketatanegaraan Islam, dikaji dalam fiqh siyasah dan telah dikenal pula trias politica yaitu sulthah altasyri'iyyah (kekuasaan legislatif), sulthah al-thanfidziyah (kekuasaan eksekutif), Sulthah al-qadha'iyyah (kekuasaan yudikatif).

\section{DAFTAR KEPUSTAKAAN}

A.Djazuli. (2003). Figh Siyasah. Jakarta: Kencana Prenada Media Group.

A.R, F. Y. (2012). Mekanisme Checks and Balances Dalam Sistem

Ketatanegaraan Indonesia pascaAmandemen UUD 1945. Simbur Cahaya, XIX(49), 3245-3258.

Al-Maududi A.A. (1993). Sistem Politik Islam Cet II. Bandung: Mizan.

Audah, A. Q. (1957). Al-Islam wa Audhauna al-Siyasah. Kairo: Dar al-Kitab alArabi.

Budiardjo, M. (2008). Dasar-Dasar Ilmu Politik. Jakarta: PT Gramedia Pustaka Utama.

Bungin Burhan. (2001). Metodologi Penelitian Kualitatif Aktualisasi Metodologis ke Arah Ragam Varian Kontemporer. Jakarta: Rajawali Pers.

Gaffar, J. M. (2009). Kedudukan dan Fungsi Mahkamah Konstitusi Dalam Sistem 
Uryensi Checks and Balances Ketataneygarrana Indonnesia dan Islamm || 231

Ketatanegaraan Republik Indonesia. Jakarta: Mahakamah Konstitusi.

Indonesia, P. Undang-undang Dasar Negara Republik Indonesia Tahun 1945 (amandemen IV), 4 § (1945).

Iqbal, M. (2014). Fiqh Siyasah (Kontekstualisasi Doktrin Politik Islam). Jakarta: Prenada media Group.

Khaliq, F. A. (2005). Fikih Politik Islam. Jakarta: Amzah.

Kun Budianto. (2017). Kelembagaan Politik Islam: Konsep Konstitusi, Legislasi, Demokrasi, Ummah Dan Syura. Jurnal Studi Sosial Dan Politik, 1(2), 155-166.

Mawardi, M. A. (2008). Pengawasan dan Keseimbangan antara DPR dan Presiden dalam Sistem Ketatanegaraan RI. Jurnal Hukum IUS QUIA IUSTUM, 15(1), 60-80. https://doi.org/10.20885/iustum.vo 115.iss1.art3

Miles, Huberman, dan S. (2014). Qualitative Data Analysis: A method Sourcebook. america: United State of Amerika.

Moh Mahfud MD. (2011). Perdebatan Hukum Tata Negara Pasca Amandemen Konstitusi. Jakarta: PT. Raja Grafindo Persada.

Montisa Mariana. (2017). Check And Balances Antar Lembaga Negara Di Dalam Sistem Politik Indonesia. Logika, 1(9), 20-28. https:/ / doi.org/10.1017/CBO978110 7415324.004

Paydar, M. (2003). Legitimasi Negara Islam. (Yogyakarta: Fajar Pustaka Baru.
Pigome, M. (2011). Implementasi Prinsip Demokrasi Dan Nomokrasi Dalam Struktur Ketatanegaraan Ri Pasca Amandemen Uud 1945. Jurnal Dinamika Hukum, 11(2). https://doi.org/10.20884/1.jdh.2011 .11.2.191

Pirmansyah, M. (2014). Eksistensi Dewan Perwakilan Daerah Dalam Sistem Bikameral Di Indonesia. Jurnal Cita Hukum, 2(1), 163-184. https://doi.org/10.1017/CBO978110 7415324.004

Rahmatullah, I. (2013). Rejuvinasi Sistem Checks and Balances Dalam Sistem Ketatanegaraan di Indonesia. Jurnal Cita Hukum, 1(2). https://doi.org/10.15408/jch.v1i2.29 92

Ridwan, H. (2007). Hukum Administrasi Negara. Jakarta: RajaGrafindo Persada.

Shobron, A. H. S. dan S. (2016). Konsep Syura Menurut Hamka Dan M. Quraish Shihab. Wahana Akademika: Jurnal Studi Islam Dan Sosial, 3(2), 59. https://doi.org/10.21580/wa.v3i2.1 144

Sunarto. (2016). Prinsip Checks and Balances Dalam Sistem Ketatanegaraan Indonesia. MasalahMasalah Hukum, 45(2), 157-163.

Suparman, F. (2016). Meluruskan Fakta Sejarah Lengsernya Gus Dur. Retrieved fromhttps://www.beritasatu.com/nasiona 1/340330/meluruskan-fakta-sejarahlengsernya-gus-dur

Thaib, D. (2003). Menuju Parlemen Bikameral (Studi Konstitusional 
Perubahan Ketiga UUD 1945). Jurnal Hukum, 10(23), 85-97. https://doi.org/10.20885/iustum.vo 110.iss23.art5

Thontowi, J. (2011). Kedudukan Dan Fungsi Komisi Yudisial Republik Indonesia. Jurnal Hukum, 18(2), 185302.

https://doi.org/10.20885/iustum.vo 118.iss2.art8
Warjiati, S. (2012). Sistem Ketatanegaraan Indonesia Pasca Amandemen UUD 1945. Al-Daulah: Jurnal Hukum Dan Perundangan Islam, 2(2), 185-207. https://doi.org/10.15642/ad.2012.2. 2.185-207

Zed, M. (2007). Metode Penelitian Kepustakaan. Jakarta: Yayasan Obor Indonesia. 